\title{
Designing and explaining the model of knowledge workers' retention with emphasis on HRM practices
}

\author{
Reza Rasouli ${ }^{\mathrm{a}}$, Alireza Mooghali ${ }^{\mathrm{b}}$, Mohammad Mousavi ${ }^{\mathrm{b}}$ and Mehdi Rashidi ${ }^{\mathrm{c}^{*}}$
}

\author{
Article history: \\ Received December 1, 2012 \\ Received in revised format \\ 2 March 2013 \\ Accepted 8 March 2013 \\ Available online \\ March 92013 \\ Keywords: \\ Knowledge workers \\ Intent to stay \\ Retention \\ HRM practices
}

${ }^{a}$ Associate Professor, Department of Public Administration, Payame Noor University, Iran

${ }^{b}$ Associate Professor, Department of Public Administration, Payame Noor University, Iran ${ }^{c}$ PhD candidate in Human Resource Management, Faculty member, Payame Noor University, Iran

\section{Introduction}

In today's competitive knowledge-based economy and trade, recruiting, developing and maintaining high-performance knowledge workers with high potential, at all organizational levels play essential role on the success of business firms. There are several discussions on knowledge workers' retention and creating a specific sense that organizations need them. In this view, market becomes a place of interchanging the talent that people select when and where work and present their talent. In order to attract, develop, manage and maintain such staff, organizations should do any attempt; and this is what creates an ongoing and inimitable competitive advantage for organizations (Briscoe, 2008).

Corresponding author. Tel: +985342221804, Fax: 985342227999

E-mail: mirashidi@yahoo.com (M. Rashidi)

C) 2013 Growing Science Ltd. All rights reserved.

doi: $10.5267 /$ j.msl.2013.03.01 
Companies normally try to improve in managing traditional technologies and they are faced with a bigger challenge, which is how managers need to manage knowledge workers to achieve long-term success for their organizations. Obviously, we do not expect organizations to access skilled workers with no effort and to face with this challenge, managers should learn, continuously and this is what creates a competitive advantage for the organization (Armstrong, 1999).

According to Nonaka et al. (2000), knowledge and skills create competitive advantage for organizations. Because the knowledge and skills enable the organization to be innovating in products, services, processes, or it can run products, services and existing processes in more efficient and more effective way. In addition, business units with qualified knowledge workers, have greater capabilities to manage knowledge. Organizations should perform different activities to persuade knowledge workers stay in organization. Undoubtedly, human resource management activities are the primary part of this bustle.

Hence, the main problem of this study is to determine the relationship between human resource management practices and job satisfaction, organizational commitment, trust in management and intention to stay of knowledge workers and to examine the predictability of their intent to stay with HRM practices through the intermediary variables of job satisfaction, organizational commitment and trust in management in surveyed organizations.

\section{Material and methods}

\subsection{Staff turnover theories}

Some experts have proposed a comprehensive model of behavioral intentions in describing the relationships between attitudes and behavior, which has been widely used. According to Ajzen model, intent of individuals handling a particular behavior is the best predictor of behavior. For instance, the most precise approach to determine whether a person resigns from his/her job is to investigate his/her intention to resign. There are some studies to believe that behavioral intentions had been a better predictor of job satisfaction or organizational commitment for staff turnover rate. However, the question of their intentions; enables managers to forecast who will resign, but does not justify on their turnover. Therefore, to understand why workers behave, it is necessary that the attitudes of people in the area be examined. In addition, we need to investigate the attitudes toward a behavior and perceived norms about behavior impact behavioral intentions. Attitudes and norms in turn are detected by individual beliefs (Rezaeian, 2001). The principal theory on employee turnover was developed by March and Simon's (1958). Their propositions about organizational behavior established the foundation of much modern turnover theory. Utility experienced by contribution to the firm's productivity might provide the employee with a sense of work ownership. Utility experienced by inducements may cause the individuals to feel recognized, valued and rewarded for their contributions to the firm's productivity. March and Simon (1958) argued that an increase (decrease) in inducement utilities over contribution utilities leads to a decrease (increase) in the chances of an employee wishing to leave the organization. A balance between two utilities is apparent in the theorists' argument: The proportion of each utility experienced may well indicate whether the worker feels satisfied or dissatisfied with the current job.

Contribution and inducement utilities also influence the individual's perception of their internal and external environment (the current job and perceived job alternatives available in the internal and external job market, respectively) (Lee et al., 2008). Internal organization factors might impact desirability of mobility and therefore the worker's satisfaction of the current job. The existence of alternatives in the external environment could possibly influence the worker's perceived ease of movement. Therefore, the potential satisfaction presented by alternatives seems influential over an individual's current job satisfaction (March \& Simon, 1958). 


\subsection{Expansion of the employee turnover paradigm}

Literature suggests that the process preceding voluntary turnover is complex, and there is no standard turnover model in existence (Morrell et al., 2004). Although there is speculation of the lack of a dominant turnover structure, based on March and Simon's (1958), turnover model incorporating desirability of mobility and desirability of alternatives (ease of movement) has numerous theoretical expansions by Mobley (1977) and associates with other theorists (Mobley et al, 1978; Mobley et al., 1979). Those methodological concerns of prior organizational behavior research raised by March and Simon (1958) may well have facilitated Mobley's (1977) sound development of the turnover process, given in Fig. 1.

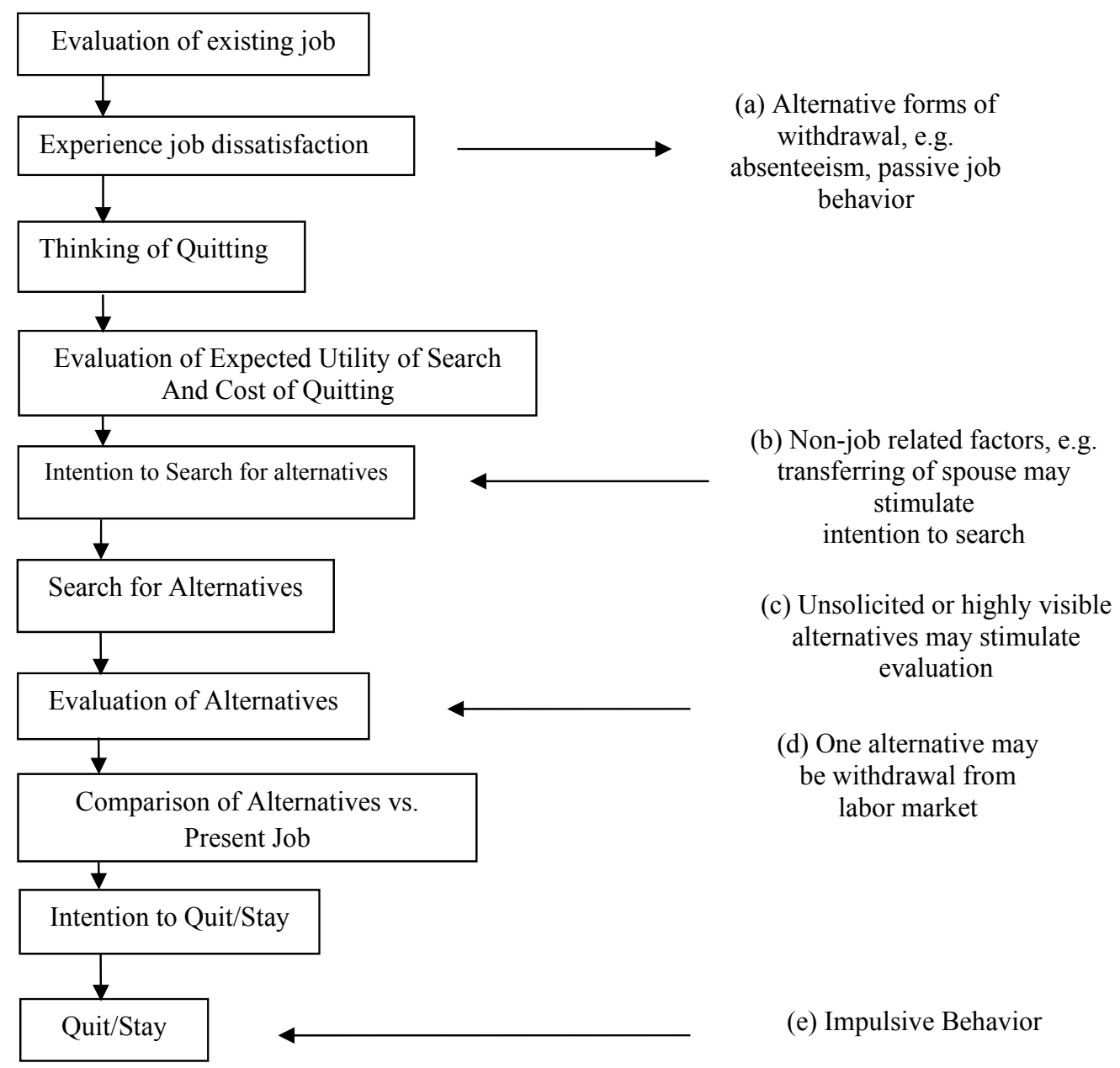

Fig. 1. Employee turnover decision process, Source: Mobley (1977)

\subsection{The impact of HRM practices on knowledge workers}

Earlier studies in human resource management have highlighted the significance of the HR-attitudes connection by positing that HRM can influence organizational outcomes through its influence on workers' attitudes (Appelbaum et al., 2000; Macky \& Boxall, 2007; Meyer \& Smith, 2000; Purcell et al., 2003, 2009). Predominantly, scholars have emphasized the relative importance of the connection between HRM and, workers' organizational commitment and job satisfaction (Appelbaum et al., 2000; Chang, 2005; Gerhart, 2005; Macky \& Boxall, 2007; Purcell et al., 2003; Whitener, 2001). 
Chew (2004) investigated the effect of human resource activities on the sustainability of core employees of Australian firms. He found that HRM practices including organizational fit, compensation, training and development were impressive on organizational commitment. In addition, he impressed that organizational factors including relationships of working groups, corporate culture and policy, work environment and variables such as age and gender were influencing on organizational commitment of key staff. Finally, he noted the effect of organizational commitment on employees' willingness to stay (Chew, 2004). Mudor et al. (2011) explained that job satisfaction could influence on job satisfaction. Martin et al. (2011) addressed this issue and examined the effect of HRM practices including hiring and employment, training and development, compensation, monitoring and evaluating on employee retention. Utilizing structural equation modeling, the study obtained the impact of human resource practices on organizational commitment 0.806 and on job satisfaction 0.638 , directly. In addition, the path coefficient of job satisfaction influenced on organizational commitment was 0.717 . Finally, organizational commitment and job satisfaction were found to be effective with the ratios of -0.652 and -0.619 , respectively. Another study at Bath University investigated three variables including human capital, social capital and organizational capital mediator in association with HRM practices and organizational commitment and job satisfaction of knowledge workers (Farah, 2011). Other researchers studied the trust as a moderator factor in the relationship between human resources practices and employee attitudes (Laura et al., 2011) where they studied the packages of empowerment, motivation and participation. Based on the research findings, trust influenced on both the general relationship between human resources practices and staff attitudes and there were some relationships between employee incentive programs and attitude.

Hence, using research literature and models of motivation, the behavioral intentions model of Ajzen, employees' turnover theories, research findings and researcher innovation, the initial theoretical model was formulated and after running Delphi technique and getting the experts' opinions, the final theoretical model of research was considered in Fig. 2.

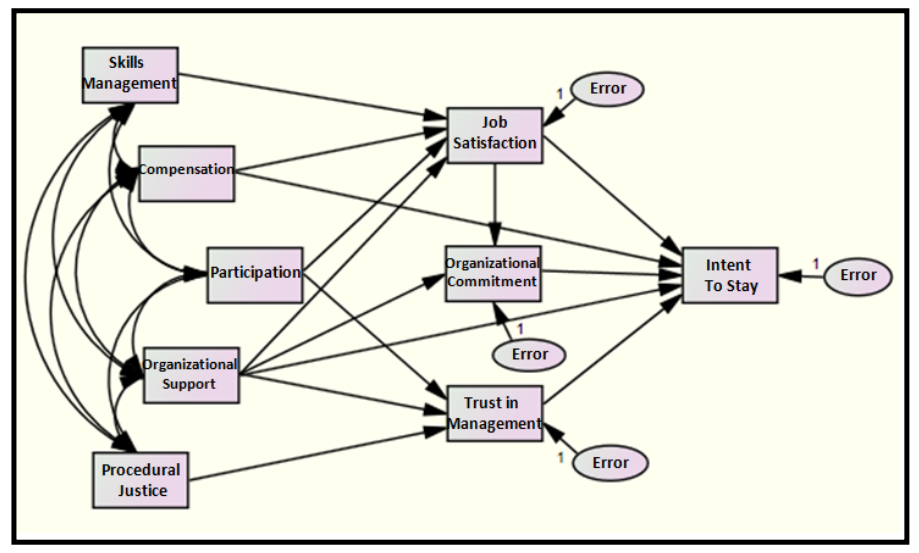

Fig. 2. Path model for explanation the relations between research variables

Research hypotheses based on the theoretical research model were developed as follows:

$\boldsymbol{H}_{1}$. HRM practices in skills development of knowledge workers influence on their job satisfaction.

$\boldsymbol{H}_{2}$. Knowledge workers' opportunity for participation, influence on their job satisfaction.

$\boldsymbol{H}_{3}$. Perceived organizational support, influence on knowledge workers' job satisfaction.

$\boldsymbol{H}_{4}$. Knowledge workers' salary and benefits influence on their job satisfaction.

$\boldsymbol{H}_{5}$. Knowledge workers' opportunity for participation, influence on their trust in managers. 
$\boldsymbol{H}_{6}$. Perceived organizational support, influence on knowledge workers' trust in managers.

$\boldsymbol{H}_{7}$. Perceived procedural justice, influence on knowledge workers' trust in managers.

$\boldsymbol{H}_{8}$. Knowledge workers' job satisfaction, influence on organizational commitment.

$\boldsymbol{H}_{9}$. Perceived organizational support, influence on knowledge workers' organizational commitment.

$\boldsymbol{H}_{10}$. Knowledge workers' salary and benefits influence on their intent to stay.

$\boldsymbol{H}_{11}$. Knowledge workers' organizational commitment, influence on their intent to stay.

$\boldsymbol{H}_{12}$. Knowledge workers' trust in managers, influence on their intent to stay.

$\boldsymbol{H}_{13}$. Knowledge workers' job satisfaction, influence on their intent to stay.

$\boldsymbol{H}_{14}$. Perceived organizational support, influence on knowledge workers' intent to stay.

\subsection{Research Methodology}

The purpose of research is to identify causal relationships between HRM practices, organizational commitment, job satisfaction, trust in management and knowledge workers' intent to stay. Typically, using path analysis, we obtain quantitative estimates of the causal relationships among a set of variables (Hooman, 2009). By considering literature, the initial theoretical model was formulated and after running Delphi technique and getting the experts opinions, the final theoretical model of research was obtained. In this model, HRM practices including skills development, participation in information, organizational support, salary and benefits and procedural justice were considered as independent variables, job satisfaction, organizational commitment and trust in managers are regarded as mediator variables and intent to stay was the dependent variable.

Statistical population of this research covers all faculty members and institutions of higher education in South Khorasan province, which was given to 660 people from the internal data of organizations. For estimating the sample size were used of the two methods: a) Cochran formula; the number of samples using Cochran formula with respect to the number of 660 persons, and with a view to ensuring a $95 \%$ and success ratio $(50 \%)$, was 244 :

$$
n=\frac{\frac{\mathrm{Z}^{2} \frac{\alpha}{2}(\mathrm{P})(1-\mathrm{P})}{\varepsilon^{2}}}{1+\frac{1}{\mathrm{~N}}\left(\frac{\mathrm{Z}^{2} \frac{\alpha}{2}(\mathrm{P})(1-\mathrm{P})}{\varepsilon^{2}}-1\right)}=\frac{384.16}{1.5805}=243.05 \cong 244
$$

b) Morgan Table Sampling: for the population, $n=244$ (Sekaran, 2011). Considering the above two methods, we have distributed 270 questionnaires among members of the community and finally 256 questionnaires were considered eligible and they were analyzed. Data collection instrument for this study is a questionnaire. Therefore, to measure HRM practices we have used the questionnaire employed based on the work accomplished by Giauque et al. study (2010) built based on exploratory interviews and one other word (Roger \& Vivien questionnaire, 1998). To measure job satisfaction, utilized Linz questionnaire (2003) and to measure organizational commitment we have used Meyer et al. (1993) questionnaire. To assess the trust in managers, Tzafrir questionnaire (2007) has been used. Assessment of intend to stay was accomplished using the questionnaire developed by Hunt et al. (1981). Except for assessment of intend to stay, the Likert 5-choice range in instruments was used.

To retest the reliability of instruments, an initial sample including 30 questionnaires were used. Analyzing gathered data, showed the Cronbach's alpha for the scales in order: 0.543 for the opportunity to participate, 0.696 of skills development, 0.772 for salary and benefits, 0.788 for organizational support, 0.560 for procedural justice, 0.631 for job satisfaction, 0.736 for organizational commitment, 0.835 for trust in managers, and 0.824 for intent to stay. These values indicate that the reliabilities of scales are acceptable. Validity of the questionnaire was confirmed from both verifying by experts and scholars and standardizing of the instrument. 


\section{Results}

We first present statistical observations based on the participants' personal characteristics. In our survey, 66.8 percent of respondents were employed in public universities and colleges and 33.2 percent in the private sector. In terms of educational backgrounds, $35.2 \%$ of the participants hold masters' degree, $64.8 \%$ hold $\mathrm{PhD}$ degree. While $32 \%$ of the respondents were male, $68 \%$ of them were female. In addition, Fig. 3 shows frequencies of their job experiences.

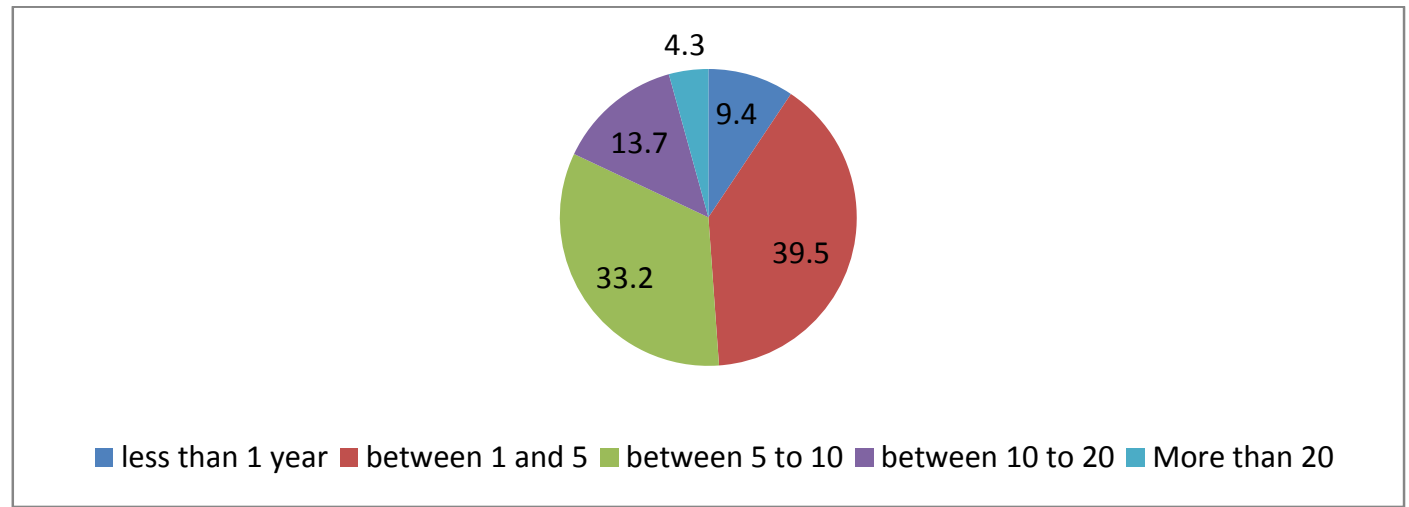

Fig. 3. The frequency of job experiences

As we can observe from Fig. 3, 9.4 percent of the participants had less than one year of work experience, $39.5 \%$ had between 1 and 5 years, 33.2\% between 5 to $10,13.7 \%$ between 10 to 20 years and $4.3 \%$ had more than 20 years of work experience.

For data analysis and testing research hypotheses, path analysis and AMOS software were used. The results for the coefficient values and the number of significant have shown in Table 1.

Table 1

The standardized path coefficients of developed model

\begin{tabular}{llllll}
\hline Hyp. & standardized path coefficients & Sig. & Forecast (\%) & Explanation (\%) & Result of test \\
\hline H1 & 0.148 & 0.028 & 14.8 & 2.2 & Confirming the hypothesis \\
H2 & 0.092 & 0.107 & 9.2 & 0.85 & Rejecting the hypothesis \\
H3 & 0.280 & 0.000 & 28 & 7.8 & Confirming the hypothesis \\
H4 & 0.253 & 0.000 & 25.3 & 6.4 & Confirming the hypothesis \\
H5 & 0.185 & 0.000 & 18.5 & 3.4 & Confirming the hypothesis \\
H6 & 0.522 & 0.000 & 52.2 & 27.2 & Confirming the hypothesis \\
H7 & 0.235 & 0.000 & 23.5 & 5.5 & Confirming the hypothesis \\
H8 & 0.334 & 0.000 & 33.4 & 11.1 & Confirming the hypothesis \\
H9 & 0.223 & 0.000 & 22.3 & 5 & Confirming the hypothesis \\
H1 & -0.257 & 0.000 & 25.7 & 6.6 & Confirming the hypothesis \\
H12 & 0.305 & 0.000 & 30.5 & 9.3 & Confirming the hypothesis \\
H13 & -0.090 & 0.003 & 20.3 & 4.1 & Confirming the hypothesis \\
H14 & 0.408 & 0.136 & 9 & 8.1 & Rejecting the hypothesis \\
\hline
\end{tabular}

According to the results of Table 1, except hypotheses 2 and 13, other hypotheses are significant, statistically. In the first hypothesis, the influence of skills development on job satisfaction (0.148) is significant statistically $(\mathrm{p}<0.05)$. Standardized path coefficient indicates that the dependent variable (job satisfaction) can be predicted in 14.8 percent by independent variable (skills development). In addition, the 2.2 percent of job satisfaction variances can be explained and justified by skills development. This analysis can be extended to other hypotheses, similarly. The results of indirect effects on the main dependent variable (intention to stay) are expressed in Table 2. 
Table 2

Indirect influence on the intention to stay

\begin{tabular}{ll}
\hline Indirect effects on the intention to stay & Coefficient of indirect effects \\
\hline Job satisfaction $\rightarrow$ organizational commitment $\rightarrow$ intent to stay & $0.33 \times 0.31=0.102$ \\
Organizational support $\rightarrow$ organizational commitment $\rightarrow$ intent to stay & $0.22 \times 0.31=0.068$ \\
Opportunity to participate $\rightarrow$ trust in managers $\rightarrow$ intent to stay & $0.18 \times 0.20=0.036$ \\
Organizational support $\rightarrow$ trust in managers $\rightarrow$ intent to stay & $0.52 \times 0.31=0.161$ \\
Procedural justice $\rightarrow$ trust in managers $\rightarrow$ intent to stay & $0.24 \times 0.31=0.074$ \\
Skills development $\rightarrow$ job satisfaction $\rightarrow$ organizational commitment $\rightarrow$ intent to stay & $0.15 \times 0.33 \times 0.31=0.015$ \\
Salary $\rightarrow$ job satisfaction $\rightarrow$ organizational commitment $\rightarrow$ intent to stay & $0.25 \times 0.33 \times 0.31=0.025$ \\
$\begin{array}{l}\text { Opportunity to participate } \rightarrow \text { job satisfaction } \rightarrow \text { organizational commitment } \rightarrow \text { intent } \\
\text { to stay }\end{array}$ & $0.09 \times 0.33 \times 0.31=0.009$ \\
$\begin{array}{l}\text { Organizational support } \rightarrow \text { job satisfaction } \rightarrow \text { organizational commitment } \rightarrow \text { intent to } \\
\text { stay }\end{array}$ & $0.28 \times 0.33 \times 0.31=0.028$ \\
\hline
\end{tabular}

Results in Table 2 show that organizational support through variable of trust in managers has the most indirect forecasting power for knowledge workers' intention to stay and then job satisfaction through variable of organizational commitment can predict the intention to stay with slight difference. In this section, the most important indicators of general fitting for developed model are presented in Table 3.

Table 3

Results of general fitting indicators for developed model

\begin{tabular}{llll}
\hline index & Quantity & Acceptable domain & result \\
\hline CMIN/DF & 1.853 & 1 to 5 & Confirming the model \\
NFI & 0.976 & $>0.90$ & Confirming the model \\
RFI & 0.929 & $>0.90$ & Confirming the model \\
IFI & 0.989 & $>0.90$ & Confirming the model \\
TLI & 0.966 & $>0.95$ & Confirming the model \\
CFI & 0.989 & $>0.90$ & Confirming the model \\
RMSEA & 0.058 & $<0.09$ & Confirming the model \\
HOELTER & 242 & $>200$ & Confirming the model \\
\hline
\end{tabular}

Therefore, it can be concluded that in addition to the variables are reasonably correlated with each other, most of the research hypotheses and putative predictive variables in the model have been confirmed as well. After pruning, the research final model was considered as Fig. 3.

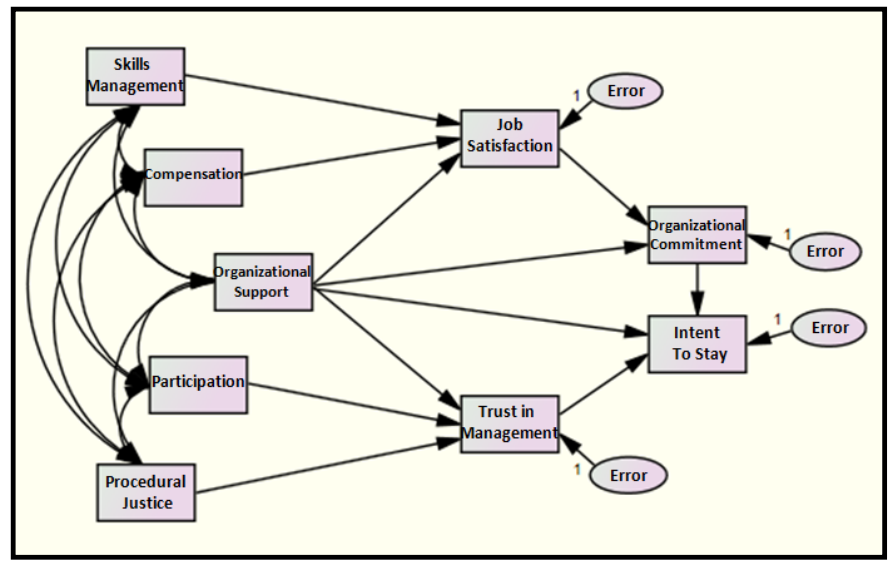

Fig. 3. The research final model 


\section{Conclusion and discussion}

This study was arranged to design and to explain the knowledge workers' retention model in which the relationships between HRM practices, job satisfaction, organizational commitment, trust in managers and intent to stay was considered. The results showed that the highest effect coefficient (0.52) belongs to the effect of organizational support on trust in managers. In addition, among the variables influencing job satisfaction and intent to stay, organizational support had the highest impact factor (respectively 0.28 and 0.41 ). Therefore, the internal variables of trust in management, job satisfaction and intention to stay more than other variables affecting, is a function of organizational support.

Organizational commitment in knowledge workers is created difficulty and as noted in literature these employees had a strong potential for turnover. In the present study, among predictor variables, only the variable of organizational support was glaring as a predictor of organizational commitment for such employees with an impact coefficient of 0.22 .

The final variable in this study is intent to stay. Based on the results obtained in the study, most direct predictive power for intent to stay is associated with the organizational support with an impact coefficient of 0.41. Any organization, which tries to utilize knowledge workers, in the first stage for their retention must increase perception of organizational support. Support practices are all those management activities, which give employees significant room to maneuver on organizing their private and professional lives, enabling them to undertake their duties, efficiently within an organizational context, which promotes initiative-taking and listening. Support corresponds to implement minimal organizational conditions with a view of enabling knowledge workers to achieve fulfillment. In this sense, this study underlines the importance of HRM practices focusing on employee development. In the precise context of our study, organizational support mainly consists in implementing flexible working conditions, giving room for maneuver to the employees, facilitating their initiatives and listening to them. In this respect, the results of this study confirm the conclusions of previous research (Barnard \& Rodgers, 2000). Perceived organizational support is the result of the relationship between employees and the organization. This relationship is based on the types of interactions that take place between employees and the organization. From the organizational researchers' point of view, the relationship between employees and managers not only come from resources such as money, services or information but also it covers emotional sources like the approval, respect and support. Support of the organization creates an obligation to compensate. Therefore, employees who receive high level of support, probably compensate this support with positive attitude and favorite work behaviors.

The results also show that if knowledge workers trust in their managers, their intention to stay will increase. Therefore, managers who concern about employees retention, must attempt to do any action that creates the climate of trust in organization. In this context, present study reminds the practices like organizational support, employee participation in information and decision making process and justice in transactions and procedures.

Results, indirect effects on the intention to stay, show that organizational support through variable of trust in managers has the most indirect forecasting power for knowledge workers' intention to stay in organizations. In addition, job satisfaction through variable of organizational commitment predicting the intention to stay with slight difference is the second important item. Based on these results, it is possible to perform HRM practices like skills development; increase in salaries and improvement in organizational support to raise job satisfaction and finally intent to stay of knowledge workers.

Like all studies in the field of social sciences, this one contains inherent limitations associated with the methodological and conceptual choices made. While a cluster of serious indicators indicates that 
certain HRM tools influencing the organizational commitment and intent to stay of knowledge workers, there are probably other variables, not taken into account in this research, which may have significant influences on the degree of organizational commitment (for example, pride of belonging, organizational values, the $\mathrm{P}-\mathrm{O}$ fit, etc.).

\section{References}

Appelbaum, E., Bailey, T., \& Berg, P. (2000), Manufacturing Advantage: Why High-Performance Systems Pay Off, Ithaca: ILR Press.

Armstrong, G. (1999). Institute for personnel and Development, United kingdom.

Barnard, M. E., \& Rodgers, R. A. (2000). How are internally oriented HRM policies related to highperformance work practices? Evidence from Singapore.International Journal of Human Resource Management, 11(6), 1017-1046.

Briscoe, D. (2008). 10. Talent management and the global learning organization. Smart Talent Management: Building Knowledge Assets for Competitive Advantage, 195.

Chang, E. (2005). Employees' overall perception of HRM effectiveness. Human Relations, 58(4), 523-544.

Chew, J. C. L. (2004). The influence of human resource management practices on the retention of core employees of Australian organisations: An empirical study (Doctoral dissertation, Murdoch University).

Farah, A. (2011). The role of human, social and organizational capital in the interconnections between knowledge workers' perception in HR practices and, their organizational commitment and job satisfaction (Doctoral dissertation, University of Bath)

Gerhart, B. (2005). Human resources and business performance: Findings, unanswered questions, and an alternative approach. Management Revue, 16(2), 174-185.

Giauque, D., Resenterra, F., \& Siggen, M. (2010). The relationship between HRM practices and organizational commitment of knowledge workers. Facts obtained from Swiss SMEs. Human Resource Development International, 13(2), 185-205.

Hooman, H.A. (2009). Structural Equation Modeling and software application, Tehran: SAMT publication.

Hunt, J. G., Osborn, R. N., \& Martin, H. J. (1981). A multiple influence model of leadership (Technical report no. 520). Alexandria, Virginia: U.S. Army Research Institute for the Behavioral and Social Sciences.

Innocenti, L., Pilati, M., \& Peluso, A. M. (2011). Trust as moderator in the relationship between HRM practices and employee attitudes. Human Resource Management Journal, 21(3), 303-317.

Lee, T.H., Gerhart, B., Weller, I., \& Trevor, C.O. (2008). Understanding voluntary turnover: Pathspecific job satisfaction effects and the importance of unsolicited job offers. Academy of Management Journal, 51(4), 651-671.

Linz, S. J. (2003). Job satisfaction among Russian workers. International Journal of Manpower, 24(6), 626-652.

Macky, K., \& Boxall, P. (2007), The relationship between 'high-performance work practices' and employee attitudes: an investigation of additive and interaction effects, The international Journal of Human Resource Management, 18(4), 537-567.

March, J.G., \& Simon, H.A. (1958). Organizations. New York: John Wiley and Sons.

Martin, M. J. (2011), Influence of human resource practices on employee intention to quit, Unpublished doctoral dissertation, Faculty of Virginia Polytechnic Institute and State University.

Meyer, J.P., Allen, N.J., \& Smith, C.A. (1993). Commitment to the organizations and occupations: Extension and test of three-component conceptualization. Journal of Applied Psychology, 78, 53851.

Meyer, J., \& Smith, C.A. (2000). HRM practices and organizational commitment: test of a mediation model. Canadian Journal of Administrative Sciences, 17 (4), 319-331. 
Mobley, W.H. (1977). Intermediate linkages in the relationship between job satisfaction and employee turnover, Journal of Applied Psychology, 62(2), 237-240.

Mobley, W.H., Griffeth, R.W., Hand, H.H., \& Meglino, B.M. (1979). Review and conceptual analysis of the employee turnover process. Psychological Bulletin, 86(3), 493-522.

Mobley, W.H., Horner, S.O., \& Hollingsworth, A.T. (1978). An evaluation of precursors of hospital employee turnover. Journal of Applied Psychology, 63(4), 408-414.

Mudor, H., \& Tooksoon, P. (2011). Conceptual framework on the relationship between human resource management practices, job satisfaction, and turnover.Journal of Economics and Behavioral Studies, 2(2), 41-49.

Nonaka, I., Toyama, R., \& Nagata, A. (2000). A firm as a knowledge-creating entity: a new perspective on the theory of the firm. Industrial and corporate change, 9(1), 1-20.

Purcell, J., Kinnie, N., Hutchinson, S., Rayton, B., \& Swart, J. (2003). Understanding the People and Performance Link: Unlocking the black box, London: Chartered Institute of Personnel and Development.

Purcell, J., Kinnie, N., Swart, J., Rayton, B., \& Hutchinson, S. (2009). People Management and Performance, London: Routledge.

Rezaeian, A. (2001). Management of Organizational Behavior, Tehran: SAMT publication.

Seifert, R., \& Tegg, V. (1998). Management development in the British and Irish civil services. Journal of Management Development, 17(9), 686-698.

Sarmad, Z., Bazargan, A., \& Hejazi, E. (2009). Research Methods in Behavioral Sciences, Tehran: Agah Publication.

Sekaran, U. (2011). Research methods in management (Sabeai and Shirazi, Translators), Tehran: Center for Public Management.

Tzafrir, S. S. \& Gur, A. B. A. (2007). HRM Practices and Perceived Service Quality: The Role of Trust as a Mediator, Research and Practice in Human Resource Management, 15(2), 1-20.

Whitener, E. M. (2001). Do "high commitment" human resource practices affect employee commitment? A cross-level analysis using hierarchical linear modeling. Journal of Management, $27(5), 515-535$. 